Forum $2021 \cdot 36: 81$

https://doi.org/10.1007/s12312-020-00893-x

Online publiziert: 11. Januar 2021

C) Springer Medizin Verlag $\mathrm{GmbH}$, ein Teil von

Springer Nature 2021

HAMBURGER

KREBSGESELLSCHAFT E.V.

Hamburger Krebsgesellschaft e.V.

Hamburg, Deutschland

\title{
Nach 28 Jahren - Wechsel im Vorsitz der Hamburger Krebsgesellschaft
}

Im Rahmen der letzten Telefonkonferenz der Sektion A hat sich Herr Prof. Kleeberg nun nach 28 Jahren im Dienste der Krebsgesellschaft von seinen Mitstreitern und Mitstreiterinnen verabschiedet und sich für die vertrauensvolle Zusammenarbeit bedankt.

Für die Zukunft und für den gewählten Nachfolger, Prof. Dr. Carsten Bokemeyer, gibt es eine breite Basis, die Hamburger Krebsgesellschaft weiterzuentwickeln und dabei die Balance zwischen den verschiedenen Schwerpunkten zu wahren. Bokemeyer, ebenfalls Facharzt für Innere Medizin und für Hämatologie/Internistische Onkologie, ist als stellvertretender Vorsitzender bereits seit 2011 Mitglied im Vorstand der HKG. Wir freuen uns auf eine weiterhin gute Zusammenarbeit und wünschen Herrn Prof. Bokemeyer viel Erfolg bei seiner neuen Aufgabe.

\section{Korrespondenzadresse}

\section{Franziska Holz}

Hamburger Krebsgesellschaft e.V. Butenfeld 18,

22529 Hamburg, Deutschland

f.holz@krebshamburg.de

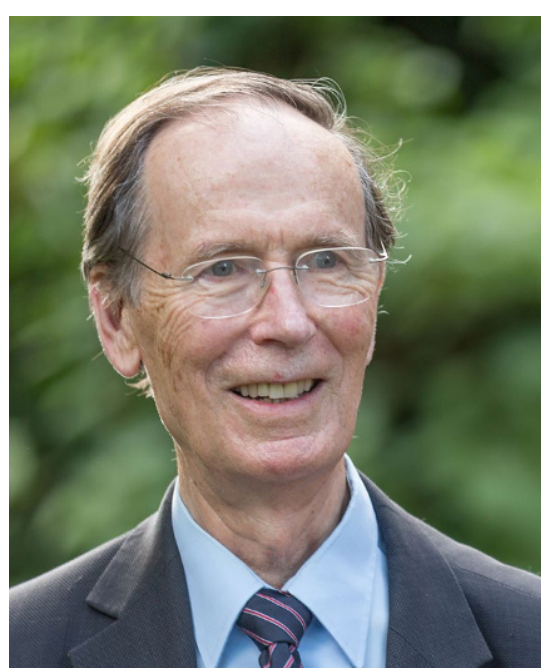

$\Delta$ Prof. Dr. Ulrich Kleeberg (@ privat)

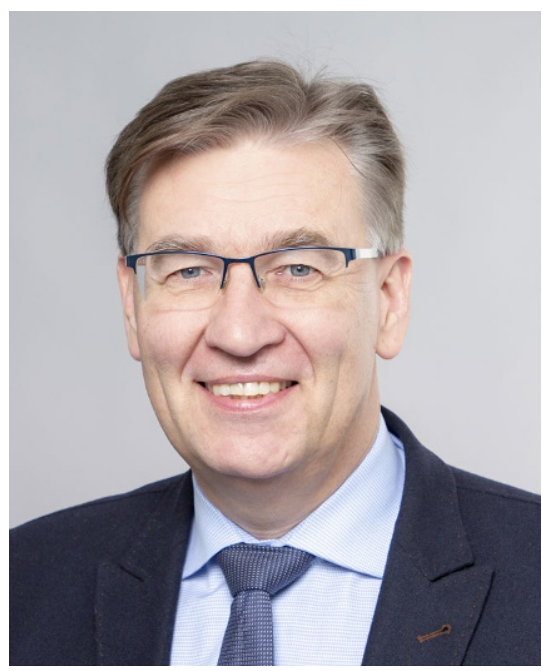

\ Prof. Dr. Carsten Bokemeyer (@ privat) chen Prävention und Patientenberatung in Hamburg und weit darüber hinaus und machte während seiner langen Amtsperiode stets seinen Einfluss auf die Gesundheitspolitik geltend. Besonders im Fokus stand für ihn immer die Verbesserung der Behandlung und Versorgung von Krebspatienten und ihren Angehörigen. 